\title{
Imagem corporal de mulheres de assentamento de reforma agrária
}

\author{
Physical aspects of the body image of women at camps of \\ land reform
}

Iara Lázara Batista de Souza

Cátia Regina Assis Almeida Leal

Vivianne Oliveira Gonçalves

\section{Resumo:}

No espaço midiático, o culto à aparência corporal propaga a imagem de um corpo feminino bonito, jovem e magro. Com relação à mulher que vive no campo, a imagem difundida é de uma mulher alheia aos cuidados com a beleza, "desleixada". O objetivo dessa pesquisa foi avaliar a satisfação com a imagem corporal e a influência dos meios de comunicação em mulheres em um assentamento rural de Jataí-Go. Foi aplicado o Body Shape Questionnaire a 25 mulheres e realizada entrevista com oito mulheres. Os resultados indicam que maioria das participantes está satisfeita com a sua imagem corporal, embora afirmem que realizariam algum procedimento cirúrgico para fins estéticos. Apesar da convivência na cidade, a mulher assentada tem anseios diferentes, que não estão centrados em um modelo de corpo ideal.

Palavras-chave: Imagem Corporal. Meios de Comunicação. Mulher Rural. Assentamento Rural.

\begin{abstract}
:
In the mediatic space, the cult for physical appearance is propagated as a female young, beautiful and thin. Referring to the women that lives in the field, the image is of a woman strange to self-care and beauty, "sloppy". The purpose of this research was to evaluate the satisfaction with physical image and influence in the communication meanings in women of a land reform camp in Jataí-Go. It was applied the Body Shape Questionnaire to 25 women and performed interview with eight women. The results indicate that most of the participant are satisfied with their physical aspects, although affirm that would perform any surgical procedure for esthetic purposes.
\end{abstract}

Keywords: Body Image. Media. Rural Women. Rural Settlement. 


\section{Introdução}

O constructo imagem corporal é complexo e abrange vários fatores biológicos, psicológicos, emocionais e sociais - e pode ter influência externa, sendo um deles as informações que são veiculadas diariamente por meio das novas tecnologias e da mídia. Essas informações são apreendidas e internalizadas, assim, a percepção de mundo e de corpo passa a ser regida por tais influências (BARROS, 2005).

A existência de referências ideais de imagem corporal, bem como a produção intensa da mídia acerca da aparência corporal pode levar à comparação entre o próprio corpo e as referências corporais divulgadas pela mídia, causando insatisfação com o próprio corpo.

A insatisfação com a imagem corporal vêm sendo associada a distintos fatores como gênero, massa corporal, prática de atividade física, alimentação, local de moradia, entre outros fatores. No que se refere ao gênero, a maioria dos estudos indicam que as mulheres apresentam maior insatisfação com a imagem corporal (MIRANDA et al., 2012; COSTA, TORRE, ALVARENGA, 2015). Em relação à massa corporal, o baixo peso e o sobrepeso estão associados à insatisfação com a imagem corporal entre os homens, enquanto nas mulheres com sobrepeso, a insatisfação é maior (SAUR, PASIAN, 2008; PETROSKI, PELEGRINI, GLANER, 2009). Sobre a prática de atividade física, apesar das evidências científicas apontarem que essa prática reduz a insatisfação com a imagem corporal, alguns estudos demonstram que indivíduos fisicamente ativos, principalmente aqueles que participam de atividades que requerem controle de peso ou exigem manutenção da aparência corporal, podem apresentar insatisfação com a imagem do corpo maior que os inativos (DAVIS et al., 1989). Outro fator a ser analisado é o local de moradia dos indivíduos. Segundo Triches e Giugliani (2007), os indivíduos que habitam em áreas rurais são mais satisfeitos com seu corpo do que os que vivem em áreas urbanas, sendo estes mais pressionados à adoção de um modelo de beleza vigente. 
Portanto, a imagem corporal é construída por meio da influência de vários fatores, como a condição social, o meio em que o indivíduo está inserido, etc. A partir dessa reflexão, se enfatizou a imagem corporal da mulher rural. Os objetivos da pesquisa são identificar a influência dos meios de comunicação na imagem corporal de mulheres rurais no assentamento Nossa Senhora de Guadalupe em Jataí-Go, identificar se existem modas e modismos no meio rural e avaliar o nível de satisfação/insatisfação dessas mulheres com o seu corpo.

\section{Imagem corporal e influência da mídia}

A imagem corporal pode ser definida como uma construção multidimensional que descreve amplamente as representações internas da estrutura corporal e da aparência física, em relação a nós mesmos e aos outros (SCHILDER, 1999). De acordo com Tavares (2003), a imagem corporal envolve diferentes aspectos: perceptuais, subjetivos e comportamentais. $\mathrm{O}$ aspecto perceptual refere-se à precisão com que o indivíduo percebe o tamanho do corpo ou partes dele. O aspecto subjetivo refere-se às atitudes, sentimentos, cognições e avaliações que desperta o corpo (tais como satisfação, preocupação, ansiedade, etc.). $\mathrm{O}$ aspecto comportamental está relacionado com as condutas que a percepção do corpo e os sentimentos provocam, tais como comportamentos de exibição, comportamentos de fuga de situações que expõem o corpo.

$\mathrm{O}$ início das pesquisas em imagem corporal ocorre no século $\mathrm{XX}$, o enfoque principal das investigações foram os distúrbios neurológicos relacionados à percepção corporal de pacientes com lesões cerebrais. Em 1935, Paul Schilder, no livro "A imagem do corpo" trata a imagem corporal de forma mais ampla, introduzindo os aspectos mentais, sociais e afetivos (TAVARES, 2003).

Ao abordar a temática da imagem corporal, Tavares afirma que: 
A imagem corporal engloba todas as formas pelas quais uma pessoa experiência e conceitua seu próprio corpo. Ela está ligada a uma organização cerebral integrada, influenciada por fatores sensoriais, processo de desenvolvimento e aspectos psicodinâmicos. Mas não se trata diretamente de uma organização cerebral em funcionamento. Embora dependente de uma estrutura orgânica circunscrita, um "corpo humano", imagem corporal deve ser compreendida como um fenômeno singular, estruturado no contexto da experiência existencial e individual do ser humano, em um universo de inter-relações entre imagens corporais. (TAVARES, 2003, p. 15)

A satisfação corporal pode ser considerada como um dos aspectos da imagem corporal. A satisfação corporal é um sentimento positivo, por meio do qual o indivíduo percebe o próprio corpo, a insatisfação corporal é uma avaliação subjetiva de sofrimento e de descontento nas experiências de um indivíduo com seu corpo (GONÇALVES, 2014).

Segundo Damasceno et al. (2006, p. 82):

É possível que o grau de insatisfação com a imagem corporal seja o principal norteador ou incentivador para que os indivíduos iniciem um programa de atividade física ou também, em ambos os sexos, seja o responsável por inúmeras consequências negativas como distúrbios alimentares e dismorfias musculares.

Alguns estudos têm comprovado que a insatisfação com a imagem corporal aumenta à medida que a mídia veicula um determinado padrão estético, configurado por corpos magros, musculosos, com uma anatomia trabalhada a partir de horas em academias, realização de dietas e outros cuidados com o corpo (ALVARENGA et al., 2010; DAMASCENO et al., 2006). 
Especificamente em relação ao padrão corporal feminino, no Brasil, é possível identificar a existência de dois padrões de beleza: o padrão de beleza da mulher magra, mas ao mesmo tempo com um corpo musculoso e com curvas definidas, vinculado ao senso comum da cultura nacional; e o padrão vinculado à moda internacional, que apresenta um corpo feminino magro, longilíneo e sem curvas. Segundo Berguer (2010), a predominância do padrão cultural da "mulher gostosa" ocorre nos estratos sociais mais populares, enquanto o padrão da moda é o mais desejado nos estratos sociais mais altos.

O destaque ao corpo feminino na mídia tem crescido a cada dia, propagandas que mostram cada vez mais o corpo da mulher tem se aliado à marcas e à diferentes produtos. Com isso a mídia veicula diariamente a imagem de corpos sarados, magérrimos e a mulher brasileira se vê diante da ditadura da beleza, pressionada pelos dois padrões corporais femininos que coexistem na realidade brasileira, e que devem ser seguidos, como forma de aceitação e valorização social.

\section{O mundo rural e a mulher}

O meio rural é visualizado historicamente, tanto no Brasil como em todo o mundo, como tudo aquilo que sobra da cidade. Nesta perspectiva, são traçados os limites geográficos entre o campo e a cidade, em que toda a aglomeração municipalizada é tida como urbana, deixando para o restante dessas áreas a nomenclatura de rural. (LEAL, 2006)

Além do meio rural ser somente perspectivado como categoria geográfica específica, ele é também visto apenas como o local do agronegócio e do maquinário agrícola sofisticado que maximiza a produção agrícola e tira da terra a "riqueza" da nação. Todas as outras manifestações culturais do mundo rural que não seguem essa lógica capitalista são rotuladas como atrasadas.

Não há razão para que o meio rural seja associado à ideia de que os que ali permanecem não conseguiram ir para as cidades, não alcançaram 
êxito na vida, pelo contrário, os que ali estão contribuem de forma significativa para os que estão na cidade.

Das definições das áreas rurais no Brasil, Abramovay afirma que:

Há um vício de raciocínio na maneira como se definem as áreas rurais no Brasil, que contribui decisivamente para que sejam assimiladas automaticamente a atraso, carência de serviços e falta de cidadania. A definição do IBGE, para usar a expressão de Elena Saraceno (1996/99), é de natureza residual: as áreas rurais são aquelas que se encontram fora dos limites das cidades, cujo estabelecimento é prerrogativa das prefeituras municipais. $\mathrm{O}$ acesso à infraestruturas e serviços básicos e um mínimo de adensamento são suficientes para que a população se torne "urbana". Com isso, o meio rural corresponde aos remanescentes ainda não atingidos pelas cidades e sua emancipação social passa a ser vista - de maneira distorcida como “urbanização do campo". (ABRAMOVAY, 2000, p. 02)

Desta forma, o rural passa a ser visto pela sociedade como o local que não tem acesso a uma série de direitos, como saúde, lazer, saneamento, etc. À medida em que vão se constituindo esses direitos eles passam a ser vistos como urbanos, e essa imagem vai se definindo na cabeça da maioria das pessoas, de que no meio rural não é possível ter os mesmos direitos, de que é local dos desprovidos de saber, de status social, entre outros aspectos.

Wanderley (2003) afirma a particularidade deste mundo rural no contexto da sociedade globalizante. Para o autor, quaisquer que sejam suas formas espaciais e sociais, o mundo rural se define por uma dupla característica: a predominância dos espaços naturais sobre os espaços construídos e sua conformação enquanto pequeno grupo social, onde predominam as relações de proximidade e de interconhecimento.

Do ponto de vista do caráter da atividade agrária familiar, houve uma radical transformação das atividades produtivas, houve a diminuição da mão 
de obra, em contrapartida aos avanços tecnológicos, e também uma masculinização crescente no processo de trabalho, em que a mulher rural passa de um papel de fator primordial na atividade agrária à simples cuidados do lar (arrumar a casa, cuidar dos filhos, do quintal, entre outros).

A grande evasão da mulher do meio rural se dá entre outros fatores devido à falta de trabalho (ALMEIDA, 2008). A mulher rural é responsável pelo trabalho doméstico e ainda pelos cuidados com o quintal, atividades que vão desde o trato dos animais até a cultura de alimentos para o próprio consumo. Como essas atividades não geram renda, não são consideradas trabalho e em razão disso a mulher tem seu papel imperceptível nas estatísticas oficiais e aos olhos de muitas pessoas, que interpretam essas atividades como simples extensão das atividades domésticas.

A mulher do campo como já dissemos anteriormente tem muitos afazeres, por isso pode deixar de lado coisas que parecem não ser muito importantes como o cuidado com si mesma, sua aparência e cuidados com o corpo.

No entanto, um estudo realizado por Nascimento (2009), com o objetivo de conhecer o significado e as práticas de embelezamento corporal de mulheres de área rural, da cidade de Barra de Santana na Paraíba, encontrou que essas mulheres "além de possuir opiniões a respeito do que seja um corpo feminino e um corpo masculino ideal, busca e deseja ser e estar bonita" (p. 12), contradizendo a maioria das representações da imagem da mulher de área rural que são apresentadas na mídia, ou seja, a mulher desatenta à vaidade e aos cuidados de embelezamento corporal.

Especificamente em relação à insatisfação com a imagem corporal, a maioria das pesquisas são realizadas em áreas urbanas, encontrando-se poucos estudos realizados em áreas rurais (PETROSKI, PELEGRINI, GLANER, 2009), reforçando assim, a necessidade de maiores investigações relacionadas ao tema, em áreas rurais.

\section{Metodologia}


A pesquisa foi realizada no assentamento rural de reforma agrária Nossa Senhora de Guadalupe, localizado no município de Jataí, Goiás. Neste assentamento existem 53 lotes, com uma população aproximada de 114 pessoas, 78 homens e 66 mulheres (SOUZA E LEAL, 2010). Este assentamento foi escolhido por ter um número considerável de pessoas, e por ser localizado próximo à cidade, podendo, por isso, sofrer maior influência de comportamentos citadinos. Optou-se por realizar a pesquisa com todas as mulheres desse assentamento, entretanto, foi possível coletar informações com 25 das mulheres. Constatamos pouca diversidade em relação à idade das participantes, 5 mulheres estavam com idade entre $30 \mathrm{e}$ 40 anos e 20 mulheres com idade maior que 40 anos.

A essas 25 mulheres foi aplicado o Body Shape Questionnaire (BSQ), validado no Brasil por Di Pietro e Silveira (2009) para avaliar a insatisfação corporal. O questionário é composto 34 perguntas, em uma escala Linkert de 1 a 6 (1 - nunca, 2 - raramente, 3 - às vezes, 4 - frequentemente, 5 - muito frequentemente, 6 - sempre). O total de pontos obtidos no instrumento é a soma de cada resposta marcada e reflete os níveis de preocupação com a imagem corporal. Obtendo resultado menor ou igual a 110 pontos é constatado um padrão de normalidade e tido como ausência de distorção da imagem corporal. Resultado entre 110 e 138 pontos é classificado como leve distorção da imagem corporal; entre 138 e 167 é classificado como moderada distorção da imagem corporal; e acima de 167 pontos a classificação é de presença de grave distorção da imagem corporal. Os dados do questionário foram analisadas com o software SPSS 2.0 para Windows.

Para conhecer a influência da mídia na percepção da imagem corporal, foram realizadas entrevistas com oito mulheres que responderam ao BSQ. As entrevistas foram gravadas e transcritas. A análise das entrevistas foi realizada por meio da análise de conteúdo (BARDIN, 2010). Todas as participantes assinaram um Termo de Consentimento Livre e Esclarecido (TCLE). 
$\mathrm{Na}$ apresentação dos dados e discussão, se estabeleceram três categorias. A primeira diz respeito à satisfação/insatisfação das mulheres assentadas; a segunda refere-se à satisfação/insatisfação de acordo com a idade, e a terceira aborda a influência que a mídia tem na autoimagem corporal das mulheres.

\section{(In)Satisfação com a imagem corporal}

A imagem corporal é um importante componente da identidade pessoal e alterações dessa imagem podem levar a estratégias de controle de peso e realização de dietas. Entretanto, nem sempre esse controle tem potencial para melhorar a saúde, tendo em vista que a insatisfação com a aparência corporal pode levar a sérios problemas de saúde pública, como a adoção de comportamentos e condutas alimentares inadequadas, como por exemplo, a anorexia e a bulimia.

Segundo Secchi, Camargo e Bertoldo (2009), tais distorções, entendidas como um conflito entre o corpo real e o ideal, imposto na maioria das vezes pela mídia, podem influenciar as pessoas a buscarem estratégias possivelmente prejudiciais a sua saúde. A insatisfação com o corpo faz com que a mulher queira atingir um corpo que muitas vezes não condiz com seu biótipo, causando assim frustações para a mesma.

Os resultados referentes à insatisfação corporal das mulheres pesquisadas indicam que $16 \%$ apresenta alguma insatisfação com sua imagem corporal. Do total da amostra 12\% apresentaram preocupação leve, 4\% moderada e nenhuma apresentou preocupação grave, enquanto a maioria (84\%) não apresenta nenhuma insatisfação corporal.

Tabela 1- Níveis de satisfação/ insatisfação de acordo com as categorias do BSQ-34

\begin{tabular}{cccc}
\hline & & $\mathrm{N}$ & $\%$ \\
\hline \multirow{2}{*}{ Categorias do } & Nenhuma & 21 & $84 \%$ \\
BSQ-34 & Preocupação & 3 & $12 \%$ \\
& Preocupação leve & 1 & $4 \%$
\end{tabular}


moderada

Preocupação grave

0

$0 \%$

Fonte: Dados da pesquisa

Apesar da maioria dessas mulheres rurais estar satisfeita com a imagem corporal, na realização das entrevistas e quando perguntadas se alguma delas desejava fazer alguma modificação corporal por meio de procedimento cirúrgico, seis entre as oito mulheres entrevistadas relataram ter vontade de fazer alguma cirurgia plástica para fins estéticos.

A vontade de realização de cirurgias plásticas que as mulheres apresentaram vem de encontro com o desejo da maioria da população feminina do país e com o crescente número de cirurgias que estão sendo realizadas nos últimos tempos. Conforme afirma Rowe, Ferreira e Hoch (2011), citando o jornal O País, segundo a Sociedade Brasileira de Cirurgia Plástica (SBCP), entre julho de 2007 e junho de 2008, 629 mil pessoas se submeteram às cirurgias plásticas no Brasil, 69\% dos pacientes realizaram cirurgia plástica por motivos estéticos e $31 \%$ foram cirurgias reparadoras; a maioria dos pacientes são mulheres, sendo $88 \%$, enquanto os homens são 12\%. As cirurgias estéticas mais realizadas, de acordo com a SBCP, são as de prótese de mamas com 21\%; logo em seguida a lipoaspiração com 20\%; depois abdômen com 15\%; redução de mamas com 12\%, pálpebras com $9 \%$ e por fim nariz, representando $7 \%$ das cirurgias estéticas mais realizadas. $\mathrm{O}$ Brasil é conhecido como um dos países que mais realizam cirurgias plásticas no mundo, os implantes de silicone (96 mil) ultrapassaram as lipoaspirações (91 mil), até então as preferidas dos brasileiros.

As cirurgias mais realizadas também estão de acordo com os dados, já que obtivemos treze respostas na categoria que dizia apresentar vontade em fazer cirurgia em determinada parte do corpo, principalmente nas mamas (em aumentar ou realizar alguma reparação das mesmas) e lipoaspiração ou abdominoplastia. Dessa forma, embora as mulheres pesquisadas estejam satisfeitas com a aparência corporal, o desejo da maioria delas em realizar uma intervenção cirúrgica para fins estéticos demonstra que a insatisfação 
corporal têm se generalizado entre a população, sobretudo a população feminina, conforme aponta McCabe e Ricciardelli (2003).

Quando perguntadas para as mulheres o que era para elas um corpo bonito e qual a importância disso, seis das entrevistadas disseram que sinônimo de corpo bonito é um corpo magro, com "tudo em cima". Se percebe, portanto, que a padronização do corpo ideal é universal, é o corpo magro, musculoso e saudável.

Embora seja esse o padrão corporal na atualidade, segundo Samarão (2007) o corpo feminino está em constante mudança. Sua fragmentação em padrões e estilos data de séculos, sendo que os padrões corporais se modificaram conforme os interesses de cada época.

Segundo Freyre (2006, p. 210):

Os ideais de mulher, já foram gorda, frágil e fina e franzina. A verdade é que a especialização de tipo físico e moral da mulher, em criatura franzina, neurótica, sensual, religiosa, romântica, ou então gorda, prática e caseira, nas sociedades patriarcais e escravocráticas, resulta, em grande parte dos fatores econômicos, ou antes, sociais e culturais, que a comprimem, amolecem, alargam-lhe as ancas e estreitam-lhe a cintura, acentuam-lhe o arredondado das formas, para melhor ajustamento de sua figura aos interesses do sexo dominante e da sociedade organizada sobre o domínio exclusivo de uma classe, uma raça e de um sexo.

O padrão de corpo, portanto, se modificou ao longo do tempo, inspirando modos de vestir e de agir. No século XX, a obsessão é ser magra ou ter um corpo musculoso. As mulheres rurais afirmam algo que já é visível em toda a nossa sociedade, que nos dias de hoje a magreza é sinônimo de bonito, de cuidado com o corpo, e se a mulher está fora destes padrões ela é considerada feia, desleixada. Embora a mídia relacione a mulher rural com o desleixo, com a falta de cuidado, é possível perceber que 
a mulher assentada tem sim sua vaidade e que está satisfeita com sua imagem corporal.

De acordo Del Priore (2000), foram grandes as transformações do corpo da mulher brasileira, transformações muitas vezes obsessivas que nos últimos dez anos vem empurrando para o ideal preconizado pela mídia: ser bela, ser jovem, ser saudável. No geral, o que podemos afirmar a partir dos dados desta pesquisa é que as mulheres deste assentamento afirmam estar satisfeitas com a imagem corporal, ao mesmo tempo que disseram ter vontade de fazer alguma cirurgia plástica e relatam que o corpo bonito é aquele que aparece na mídia.

\section{(In)Satisfação corporal e idade}

Em relação à presença da insatisfação corporal em função da idade, a maioria das participantes entre 30 e 40 anos não apresentam insatisfação corporal, enquanto que as mulheres acima de 40 anos apresentam leve preocupação (12\%) e moderada preocupação (4\%).

Tabela 2 - Níveis de satisfação/insatisfação de acordo com os grupos de idade.

\begin{tabular}{ccc}
\hline Categorias do BSQ-34 & $\begin{array}{c}\text { Entre 30 e 40 } \\
\text { anos }\end{array}$ & $\begin{array}{c}\text { Acima de 40 } \\
\text { anos }\end{array}$ \\
\hline Nenhuma preocupação & $20 \%$ & $64 \%$ \\
Preocupação leve & $0 \%$ & $12 \%$ \\
Preocupação moderada & $0 \%$ & $4 \%$ \\
Preocupação grave & $0 \%$ & $0 \%$ \\
\hline
\end{tabular}

Fonte: Dados da pesquisa

O grupo das mulheres acima de 40 anos manifestaram insatisfação com a imagem corporal, resultado que se contrapõe aos relatados por Braggion, Matsudo e Matsudo (2000). Estes autores afirmam que os indivíduos mais velhos são menos exigentes em relação a sua aparência.

Durante a realização das entrevistas, ao serem perguntadas a respeito da prática de exercícios físicos como forma de melhorar a aparência corporal, a maioria afirmou ser importante a prática regular de exercício 
físico, cinco afirmaram achar importante a prática de exercício físico regular para fins de saúde (mulheres maiores de 40 anos), três delas praticam caminhada. Apenas uma afirmou que a prática regular de exercício físico não têm importância.

Berguer (2010) realizou um estudo com o objetivo de perceber e compreender como as mulheres brasileiras de classe média-alta pensam a construção de sua autoimagem, os modelos corporais que são suas referências, bem como as técnicas ou práticas corporais que utilizam para alcançá-los.

Na pesquisa de Berguer (2010), realizado com mulheres urbanas, se observa que mulheres acima de 40 anos são as que mais visam saúde, enquanto que as mulheres com menos 40 anos relataram praticar exercícios apenas com objetivos estéticos. O mesmo foi relatado por Alvarenga et al. (2010) que chegou à conclusão que as pessoas com idade mais avançada são as que realmente se preocupam mais com saúde, quanto aos mais novos ainda tem a estética como a maior motivação para a prática de exercícios físicos.

Ao comparar as pesquisas realizadas pelos autores citados e os resultados deste estudo, se pode inferir que as mulheres abaixo de 40 anos manifestaram estar satisfeitas com a imagem corporal o que as diferencia das mulheres urbanas, já que essas apresentam um índice maior de insatisfação com a imagem corporal. Já no caso das mulheres com idade acima de 40 anos, faixa etária que predominou entre as entrevistadas, houve uma prevalência de insatisfação com a autoimagem corporal. Uma das causas dessa insatisfação pode ser o avanço da idade, já que muitas mulheres passam a se preocupar muito nessa fase com a elasticidade do corpo, com o surgimento de rugas, com a alimentação, com a percepção de que são mais suscetíveis a doenças, percebendo, assim, a necessidade de levar um estilo de vida saudável.

Nesse sentido, ressaltamos que os motivos da insatisfação corporal apresentada podem estar ligados ao aumento do cuidado das mulheres com 
o corpo e aparência quando atingem essa faixa etária e não ao desejo de querer seguir um padrão que é imposto pela mídia e pela sociedade.

\section{(In)Satisfação corporal e mídia}

As questões referentes à influência da mídia na imagem corporal das mulheres assentadas participantes dessa pesquisa, foram abordadas durante a entrevista.

Vale ressaltar que quando a pesquisa foi realizada, fazia apenas uma semana que o assentamento passou a ter o fornecimento de energia elétrica, então, muitos ainda não possuíam televisão e os que tinham afirmavam não assisti-la. Apesar disso, deve-se levar em conta a proximidade do assentamento com a cidade, a qual a maioria da população do assentamento tem acesso constante.

Para Schilder (1999), a construção da imagem corporal ocorre pelo contato com o mundo externo, com a cultura e nas relações sociais. O interesse reside, portanto, não apenas pelo próprio corpo, mas pelo corpo do outro. Nesse sentido, a formação da imagem corporal, a qual se desenvolve e se modifica ao longo da vida do indivíduo, pode ser influenciada por diversos fatores tais como sexo, idade, mídia, e pela relação do corpo com os processos cognitivos como crença, valores e atitudes inseridos em uma cultura.

$\mathrm{Na}$ busca por um corpo perfeito muitas pessoas ultrapassam seus limites para conquistar uma aparência de modelo, um corpo ideal que é produzido pela mídia. Quando se fala em cuidado com o corpo, com a aparência corporal, a mulher é sempre a mais lembrada por esses cuidados e, consequentemente, a mais cobrada pela sociedade para estar nesses padrões estéticos preestabelecidos.

Os veículos de informação pressionam mais a mulher no que diz respeito à beleza, e induz as mulheres a consumirem cada dia mais, fazendo com que elas pensem que assim irão atingir o ideal que é proposto pelos produtos de beleza, medicamentos, dietas e cirurgias plásticas. 
Das oito mulheres entrevistadas, cinco delas disseram não assistir programas de televisão e o conteúdo transmitido por meio dela, não é importante fonte de informação sobre moda e beleza. Outros estudos, entretanto, têm ressaltado a relação entre o tempo assistindo à televisão e a insatisfação corporal, sobretudo em adolescentes (TIGGEMANN, PICKERING, 1996; CONTI, BERTOLIN, PERES, 2010). Tiggemann e Pickering (1996), por exemplo, em um estudo realizado sobre a influência da imagem corporal em adolescentes que passavam muitas horas em frente à televisão concluiu que a insatisfação corporal correlaciona-se positivamente com o total de horas que adolescentes do sexo feminino passam assistindo às novelas na televisão. Também observaram que as adolescentes que consideraram as revistas de moda como importantes fontes de informações sobre beleza e boa forma evidenciavam altos níveis de insatisfação corporal e tinham mais probabilidade de mudar seus comportamentos para modificar o peso, como fazer exercícios físicos e saltar refeições, quando comparadas com aquelas que não consideravam essas revistas importantes. Estes mesmos autores afirmam que quanto mais as mulheres se expõem à mídia, contendo alta proporção de imagens corporais ideais, maior é a probabilidade de apresentarem atitudes e comportamentos relacionados à transtornos da imagem corporal.

Assim como a maioria das mulheres afirma não assistir a programas televisivos, seis das oito entrevistadas afirmaram não ter como referência de moda e beleza atrizes ou personalidades do meio artístico. Ressalta-se que as mulheres participantes do estudo têm mais de 30 anos e afirmaram ver pouco conteúdo midiático.

Ao contrário, os estudos realizados com adolescentes ou jovens mulheres demonstraram que as que têm como referências de corpo ideal modelos, atrizes e personalidades mediáticas têm mais probabilidade de engajar-se em práticas de controle de peso anormais, e apresentam maior insatisfação com a autoimagem corporal (HEINBERG, THOMPSON, 1992; PETROSKI, PELEGRINI, GLANER, 2009). 
Ao questionar as entrevistadas, o que pensavam sobre as revistas que falam sobre moda e beleza e se tinham acesso a essas revistas, seis disseram considerar interessantes essas revistas e duas não emitiram opinião. Todas as entrevistadas disseram que não se sentem pressionadas por essas revistas a perder peso e não se sentem influenciadas para adotar um estilo de vida diferente do seu.

Um estudo desenvolvido por Santos (2008) realizou uma análise junto a quatro revistas dirigidas a mulheres: Nova, Cláudia, Boa Forma e Corpo a Corpo. A autora afirma que grande parte das capas de revistas dirigidas às mulheres têm um título que se refere à formas eficazes de mudar a aparência física. Na análise de Santos (2008), as capas das revistas pesquisadas apresentaram dez vezes mais matérias e anúncios publicitários com essa temática, do que em revistas voltadas ao público masculino. Além disso, a análise linguística do conteúdo das capas de revistas femininas realizados por Gomes e Silva (2005) enfatizam que utilizam, geralmente, verbos no imperativo, o que persuade às mulheres a desejarem o corpo estampado na capa da revista, acreditando que pode alcançá-lo, por meio de esforço e investimento.

Nas revistas, nas propagandas, nos programas de TV, no Instagram e no Facebook, os corpos vêm sendo constantemente moldados ao modelo estético corporal aceito, instigando às outras mulheres a tentar o mesmo. Se pode dizer que se trata de uma forma sutil de levar as mulheres ao consumo de produtos estéticos, cosméticos e nutricionais.

Segundo Goldenberg (2002, p. 9):

Cada indivíduo é considerado responsável (e culpado) por sua juventude, beleza e saúde: só é feio quem quer e só envelhece quem não se cuida. Cada um deve buscar em si as imperfeições que podem (e devem!) ser corrigidas. O corpo torna-se, também, capital, cercado de enormes investimentos (de tempo, dinheiro, entre outros). O corpo 'em forma' se apresenta como sucesso pessoal, ao qual qualquer mulher ou homem pode 
aspirar, se realmente se dedicar a isso. 'Não existem indivíduos gordos e feios, apenas indivíduos preguiçosos', poderia ser o slogan deste mercado do corpo. (grifos da autora)

Outro resultado dessa pesquisa revela que as mulheres assentadas gostam da maneira como se vestem. As oito entrevistadas afirmaram estar satisfeitas com a maneira como se vestem, isso pode ter relação com o não acompanhamento das revistas de moda e também em não se sentirem pressionadas a seguir sempre um padrão de moda que é imposto pela mídia. Seis das oito mulheres entrevistadas afirmaram tentar seguir um padrão de moda como pode, comprando roupas que tenham um preço justo e sem exageros ou preços altos. Todas afirmaram gostar de se arrumar e andar bem vestida de acordo com as suas possibilidades.

Comumente considerada como algo fútil ou "coisa de mulheres", segundo Paixão (2013, p. 9), "a moda é um dispositivo discursivo no qual/por meio do qual se constroem indivíduos dóceis e úteis para as sociedades pautadas na produção e no consumo, ou ainda, um dispositivo que controla a população ao produzir a ilusão de que leva ao bem-estar e à felicidade". A moda incita ao consumo e está estreitamente ligada à mídia, em que se alimenta e é alimentada, mudando constantemente, apesar de que nem todos podem acompanhar essa mudança, consumindo os looks de cada temporada.

Com relação ao uso da internet como fonte de informação, sete mulheres disseram não ter acesso nenhum a computadores e internet, apenas uma delas afirmou ter acesso contínuo a essa mídia. A internet é um veículo de grande importância na vida de mulheres urbanas, sabemos que essa rede de comunicação exerce grande influência na vida de mulheres de todas as faixas etárias, sobretudo as que vivem nas cidades. Por meio da internet é possível ter acesso a um grande acervo de conteúdo sobre moda, dietas e tendências; as redes sociais também são locais de encontro e de exposição da beleza de homens e mulheres por meio de fotos e outras publicações. A mulher rural não tendo acesso a esse tipo de veículo, por isso já estaria livre 
de uma parcela de influência que esse veículo midiático exerce sobre a maioria da população.

Diante disso, o que podemos perceber é que a mulher assentada também está preocupada com a sua beleza, é uma mulher que procura, dentro de suas possibilidades, ficar bonita. Quando perguntadas sobre o uso de cosméticos, todas afirmaram utilizar algum tipo de produto, tais como shampoo, cremes hidratantes, batons, perfumes, maquiagem, etc. Nas entrevistas, todas afirmaram utilizar esses produtos de maneira discreta, apenas para realçar uma "beleza natural”. Todas também afirmaram que não tem nenhum truque ou receita de beleza que foi transmitido pela mãe ou avó, muitas alegaram que naquele tempo não havia preocupação com isso, ou que as mulheres de antigamente não tinham vaidade.

A mídia, ao transmitir um discurso imagético sobre a mulher, também está transmitindo uma estética, um comportamento, um modo de ser. Segundo Santos (2008, p. 5), nesse discurso mediático:

A mulher deve ser sexy, porém, recatada. Deve estar bem maquilada, sem excessos (ou melhor, saber se maquiar) e usar roupas da moda (que delineiam o seu corpo, mas que não a deixem vulgar). $\mathrm{O}$ uso de saltos altos também contribui para configurar o modelo "ideal" de corpo esguio semelhante ao das modelos de passarela. (grifos da autora)

Os dados indicam que as mulheres rurais pesquisadas não seguem essa lógica de beleza e de preocupação com a imagem corporal. Se comporta de maneira independente diante de uma sociedade que prega esses valores a todo o momento. Essa mulher também é menos influenciada pela preocupação extrema com a imagem corporal. Apesar de estarem ligadas à moda, aos produtos de beleza e quererem se sentir bonitas, não ficam a todo momento fazendo comparações de seus corpos com o de atrizes ou modelos da mídia, se achando feias. Elas têm um propósito de beleza e de cuidado de 
acordo com as suas possibilidades e a maneira como vivem, como trabalham e como se sustentam.

Dessa forma, podemos afirmar que o significado da beleza para a mulher rural, não ocorre de uma única perspectiva, mas como resultado de inter-relações: de experiências, de participação política e até mesmo de localização geográfica. Talvez a própria participação dessa mulher nos movimentos sociais, contribui para formar um novo sujeito político, além de lutar por necessidades específicas e exigir maior participação nos espaços de poder dos movimentos sociais e na sociedade.

\section{Considerações finais}

Constatou-se que $84 \%$ das mulheres assentadas participantes não apresentaram insatisfação corporal, de acordo com o BSQ-34. No entanto, os dados das entrevistas evidenciam que essas mulheres têm vontade de realizar cirurgias para modificar a aparência corporal, o que nos permite concluir que, embora a insatisfação com a imagem corporal seja prevalente entre mulheres urbanas, conforme estudos prévios, o desejo de modificação corporal parece incidir entre mulheres, tanto urbanas, quanto rurais.

No que se refere à insatisfação corporal em função da idade das participantes, as mulheres mais velhas apresentaram maior insatisfação com a imagem corporal, apresentando também maior preocupação em relação à alimentação e prática de exercícios físicos. Uma das causas da insatisfação corporal apresentada nessa faixa etária pode ser o avanço da idade, já que após os 40 anos começam a surgir rugas, e o corpo já não é mais firme como antes. Outro fator, pode ser à ênfase dada pela mídia ao corpo jovem na atualidade.

Entretanto, ao analisar a influência da mídia sobre a imagem corporal da mulher assentada, os dados resultantes das entrevistas realizadas revelam que, apesar da convivência na cidade, a mulher assentada tem anseios diferentes, portanto, a representação de uma modelo corporal ideal de mulher não têm tanto influência sobre a mulher assentada. Portanto, se pode 
inferir que existe uma relação entre a satisfação corporal de mulheres deste assentamento com a não influência que os meios de comunicação exercem em suas vidas e seu comportamento.

De forma geral, desde a infância os indivíduos que residem em área rural consideram a magreza sinônimo de doença, ao contrário da imagem de extrema magreza considerada como padrão de beleza imposta pela mídia e a sociedade. Cabe, então, considerar que o ambiente e cultura do meio em que vivem essas mulheres podem influenciar a percepção da imagem corporal, tais como menor exposição à influência da mídia, ou até mesmo seus envolvimentos com os movimentos sociais, que formam nelas, ou por elas, um novo sujeito político, logo, mais crítico e menos passivo à influências externas.

\section{Referências}

ABRAMOVAY, Ricardo. Funções e medidas da ruralidade no desenvolvimento contemporâneo. Rio de Janeiro: Procam/USP, 2000.

ALMEIDA, Lize Vicente de. $O$ vestido e a enxada: a participação feminina no campo.2008. 91p. Dissertação (Mestrado em Serviço Social) Pontifícia Universidade Católica (Departamento de Serviço Social), Rio de Janeiro, 2008.

ALVARENGA, Marle dos Santos et al. Influências da mídia em universitárias brasileiras de diferentes regiões. Jornal Brasileiro de Psiquiatria, v. 2, n.59, p. 111-118, 2010.

BARDIN, Lawrence. Análise de conteúdo. 5. ed. Lisboa: Edições 70, 2010.

BARROS, Daniela Dias. Imagem corporal: a descoberta de si mesmo. História, ciências, saúde. Manguinhos, v. 12, n. 2, p. 547-54, maio-ago. 2005.

Filos. e Educ., Campinas, SP, v.11, n.1, p. 62-85, jan./abr. 2019 - ISSN 1984-9605 
BERGUER, Mirela. Felicidade é entrar num vestido "P": o culto ao corpo na sociedade urbana contemporânea. Cadernos de campo, São Paulo, n. 19 , p. $69-90,2010$.

BRAGGION, Glaucia Figueiredo; MATSUDO, Sandra Mahecha; MATSUDO, Victor Rodrigues. Consumo alimentar, atividade física e percepção da aparência corporal em adolescentes. Revista Brasileira de Ciência e Movimento, v. 8, n. 1, p. 15-21, 2000.

CONTI, Maria Aparecida; BERTOLIN, Maria Natacha Toral; PERES, Stela Verzinhasse. A mídia e o corpo: o que o jovem tem a dizer?. Ciência e Saúde Coletiva, Rio de Janeiro, v. 15, n. 4, p. 2095-2103, 2010.

COSTA, Ana Carolina Pereira; TORRE, Mariana Carvalho de Moura Della; ALVARENGA, Marle dos Santos. Atitudes em relação ao exercício e insatisfação com a imagem corporal de frequentadores de academia. Revista Brasileira de Educação Física e Esporte, São Paulo, v. 29, n. 3, p. 453-464, 2015.

DAMASCENO, Vinícius Oliveira et al. Imagem corporal e corpo ideal. Revista Brasileira de Ciência e Movimento, Brasília, v. 14, n. 1, p. 87-96, 2006.

DAVIS, Caroline J. et al. Body-image disturbances and bulimia nervosa: an empirical analysis of recent revisions of the DSM-III. Journal of Psychopathology and Behavioral Assessment, v. 11, n. 1, p. 61-69, 1989.

DEL PRIORE, Mary. Corpo a corpo com a mulher: pequena história das transformações do corpo feminino no Brasil. São Paulo: SENAC, 2000.

DI PIETRO, Monica; SILVEIRA, Dartiu Xavier da. Internal validity, dimensionality and performance of the Body Shape Questionnaire in a group of Brazilian college students. Revista Brasileira de Psiquiatria, São Paulo, v. 31, n. 1, mar. 2009. 
FREYRE, Gilberto. Sobrados e mucambos: decadência do patriarcado e desenvolvimento do urbano. 16 ed. São Paulo: Global, 2006.

GOLDENBERG, Mirian (Org.). $\mathrm{Nu}$ \& Vestido: dez antropólogos revelam a cultura do corpo carioca. Rio de Janeiro: Record, 2002.

GOMES, Isaltina Maria de Azevedo Mello; SILVA, José Carlos de Melo. Ciência, saúde e beleza nas revistas femininas. Revista Digital Comunicação e Saúde, v. 2, n. 3, p. 79 -95, dez. 2005.

GONÇALVES, Vivianne Oliveira. Imagen corporal y género: la desigual influencia de los mass media. Almería: Editorial Círculo Rojo, 2014

HEINBERG, L.J.; THOMPSON, J.K. Social comparison: gender, target importance rating, and relation to body-image disturbance. Social Behavior and Personality An International Journal, v.7, n. 1, p. 335-44, 1992.

LEAL, Cátia Regina Assis Almeida. Arapuca Armada: a educação na trama das contradições da modernização agrícola. Curitiba: Appris, 2015.

McCABE, Marita P.; RICCIARDELLI, Lina. A. Body image and strategies to lose weight and increase muscle among boys and girls. Health Psychology, v. 22, n. 1, p. 39-46, 2003.

MIRANDA, Valter Paulo Neves et al. Insatisfação corporal em universitários de diferentes áreas de conhecimento. Jornal Brasileiro de Psiquiatria. Rio de Janeiro, v. 61, n. 1, p. 25-32, 2012.

NASCIMENTO, Josilene Barbosa do. Quando a "Gata Borralheira" do sítio transforma-se na Cinderela. In: Anais do II Seminário Nacional de Gênero e Práticas Culturais. João Pessoa: Editora Universitária UFPB, 2009. p. 01-13.

PAIXÃO, Humberto Pires da. Saber, poder e sujeito no dispositivo da moda. 2013. 187 p. Dissertação (Mestrado em Letras e Linguística) -

Filos. e Educ., Campinas, SP, v.11, n.1, p. 62-85, jan./abr. 2019 - ISSN 1984-9605 
Universidade Federal de Goiás (Faculdade de Letras), Goiânia 2013.

PETROSKI, Edio Luiz; PELEGRINI, Andrea; GLANER, Maria Fátima. Insatisfação corporal em adolescentes rurais e urbanos. Motricidade, Lisboa, v. 5, n. 4, p. 13-25, 2009.

ROWE, Janaina F.; FERREIRA, Valéria; HOCH, Verena A. Influência da mídia e satisfação com a imagem corporal em pessoas que realizaram cirurgia plástica. In: Anais da IV Jornada Interestadual de Psicoterapias Corporais, Balneário Camboriú: Centro Reichiano, 2011.

SAMARÃO, Liliany. O espetáculo da publicidade: a representação do corpo feminino na mídia. Contemporânea, Rio de Janeiro, v. 5, n. 1, p. 4557, 2007.

SANTOS, Helena Miranda dos. A construção da imagem "Ideal" da mulher na mídia contemporânea. Fazendo Gênero 8 - Corpo, Violência e Poder, Florianópolis, p 01-07, 2008. Disponível em: http://www.fazendogenero.ufsc.br/8/sts/ST39/Helena_Miranda_dos_Santos 39.pdf. Acesso em 12/08/2013.

SAUR, Adriana Martins; PASIAN, Sonia Regina. Satisfação com a imagem corporal em adultos de diferentes pesos corporais. Avaliação Psicológica, Porto Alegre, v. 7, n. 2, p. 199-209, ago.2008.

SECCHI, Kenny; CAMARGO, Brigido Vizeu; BERTOLDO, Raquel Bohn. Percepção da imagem corporal e representações sociais do corpo. Revista Psicologia: Teoria e Pesquisa, Brasília, v. 25, n. 2, p. 229-36, 2009.

SCHILDER, Paul. A imagem do corpo: as energias construtivas da psique. São Paulo: Martins Fontes, 1999.

SOUZA, Iara Lázara Batista de; LEAL, Cátia Regina Assis Almeida Leal. Mulher rural no Sudoeste Goiano: indicadores demográficos. IV Congresso Centro-Oeste de Ciências do Esporte e I Congresso Distrital de 
Ciências do Esporte, 2010, Brasília. Anais do IV Congresso Centro-Oeste de Ciências do Esporte e I Congresso Distrital de Ciências do Esporte, 2010. p. 818-824.

TAVARES, Maria da Consolação G. Cunha. Imagem corporal: conceito e desenvolvimento. São Paulo: Manole, 2003.

TIGGEMANN, M; PICKERING, A.S. Role of television in adolescent women's body dissatisfaction and drive for thinness. International Journal of Eating Disorders, Oxford, v. 20, p. 199-203, 1996.

TRICHES, Rozane Márcia; GIUGLIANI, Elsa Regina Justo. Insatisfação corporal em escolares de dois municípios da região Sul do Brasil. Revista de Nutrição, Campinas, v. 20, n. 2, p. 119-128, 2007.

WANDERLEY, Maria de Nazareth Baudel. Um saber necessário: os estudos rurais no Brasil. Campinas: Editora da UNICAMP, 2012.

Submetido em: 15/08/2019

Aceito em: 15/09/2019

Publicado em: 30/10/2019 